OPEN ACCESS

Edited by:

Cristina Cadenas-Sanchez, University of Cádiz, Spain

Reviewed by:

Rute Santos,

Polytechnic Institute of

Coimbra, Portugal

William Tebar

São Paulo State University, Brazil

*Correspondence:

Markus Gerber

markus.gerber@unibas.ch

Specialty section:

This article was submitted to

Children and Health

a section of the journal

Frontiers in Public Health

Received: 24 February 2021

Accepted: 19 July 2021

Published: 19 August 2021

Citation:

Gerber M, Ayekoé SA, Beckmann J, Bonfoh B, Kouassi KB, Gba BC,

Traoré SG, Coulibaly JT, Daouda D,

du Randt R, Finda MF, Minja EG,

Gall S, Mollel GJ, Lang C, Long KZ,

Masanja H, Müller I, Nqweniso S,

Okumu FO, Probst-Hensch N,

Pühse $U$, Steinmann P, Walter $C$ and

Utzinger J (2021)

Moderate-to-Vigorous Physical

Activity Is Associated With

Cardiorespiratory Fitness Among

Primary Schoolchildren Living in Côte d'Ivoire, South Africa, and Tanzania.

Front. Public Health 9:671782.

doi: 10.3389/fpubh.2021.671782

\section{Moderate-to-Vigorous Physical Activity Is Associated With Cardiorespiratory Fitness Among Primary Schoolchildren Living in Côte d'Ivoire, South Africa, and Tanzania}

\author{
Markus Gerber 1*, Serge A. Ayekoé ${ }^{2}$, Johanna Beckmann ${ }^{1}$, Bassirou Bonfoh ${ }^{3}$, \\ Kouadio Benal Kouassi ${ }^{3,4}$, Bomey Clément Gba ${ }^{3,5}$, Sylvain G. Traorée ${ }^{3,6}$, \\ Jean T. Coulibaly ${ }^{1,3,5,7}$, Dao Daouda ${ }^{3}$, Rosa du Randt ${ }^{8}$, Marceline F. Finda ${ }^{9}$, \\ Elihaika G. Minja ${ }^{9}$, Stefanie Gall ${ }^{1}$, Getrud J. Mollel ${ }^{9}$, Christin Lang ${ }^{1}$, Kurt Z. Long ${ }^{1,7}$, \\ Honorati Masanja ${ }^{9}$, Ivan Müller ${ }^{1}$, Siphesihle Nqweniso ${ }^{8}$, Fredros O. Okumu ${ }^{9}$, \\ Nicole Probst-Hensch ${ }^{1,7}$, Uwe Pühse ${ }^{1}$, Peter Steinmann ${ }^{1,7}$, Cheryl Walter ${ }^{8}$ and \\ Jürg Utzinger ${ }^{1,7}$
}

\footnotetext{
${ }^{1}$ University of Basel, Basel, Switzerland, ${ }^{2}$ Institut National de la Jeunesse et des Sports, Abidjan, Côte d'Ivoire, ${ }^{3}$ Centre Suisse de Recherches Scientifiques en Côte d'Ivoire, Abidjan, Côte d'Ivoire, ${ }^{4}$ Unité de Formation et de Recherche des Sciences et Technologies des Aliments, Université Nangui Abrogoua, Abidjan, Côte d'Ivoire, ${ }^{5}$ Unité de Formation et de Recherche Biosciences, Université Félix Houphouët-Boigny, Abidjan, Côte d'voire, ${ }^{6}$ Unité de Formation et de Recherche, Université Peleforo Gon Coulibaly, Korhogo, Côte d'Ivoire, ${ }^{7}$ Swiss Tropical and Public Health Institute, Basel, Switzerland, ${ }^{8} \mathrm{Nelson}$ Mandela University, Gqeberha, South Africa, ${ }^{9}$ Ifakara Health Institute, Dar es Salaam, Tanzania
}

Background: Physical inactivity and low cardiorespiratory fitness (CRF) are independent cardiovascular risk factors among children, but have rarely been investigated concurrently in sub-Saharan Africa. The purpose of this study was to compare physical activity (PA) and CRF of primary schoolchildren living in Côte d'Ivoire (Cl), South Africa (ZA), and Tanzania (TZ), to test sex- and age-related differences, and to examine whether $\mathrm{PA}$ and CRF are associated with each other.

Methods: Baseline data from an ongoing cluster-randomized controlled trial were used, including 499 children from $\mathrm{Cl}$ (Taabo, 49\% girls, $M=8.0 \pm 1.6$ years), 1,074 children from ZA (Gqeberha, 49\% girls, $M=8.3 \pm 1.4$ years), and 593 children from TZ (Ifakara, $51 \%$ girls, $M=9.4 \pm 1.7$ years). PA was assessed by accelerometry and CRF by a $20 \mathrm{~m}$ shuttle-run test. The data were analyzed using multi-/univariate analyses of variance and mixed linear models.

Results: Most children met recommendations put forward by the World Health Organization for moderate-to-vigorous PA (MVPA) and achieved high CRF scores. In Cl, 89.6\% of the children met MVPA recommendations (boys: $91.7 \%$, girls: $87.4 \%$ ), whereas this rate was $76.9 \%$ in ZA (boys: $91.0 \%$, girls: 62.4\%), and 93.8\% in TZ (boys: $95.5 \%$, girls: 92.0\%). Children from TZ had the highest CRF and MVPA levels, followed by children from $\mathrm{Cl}$ and ZA. Boys had higher MVPA levels than girls, whereas girls engaged in more sedentary behavior. Sex differences were strongest in ZA. Sedentary behavior and MVPA were higher among older schoolchildren compared to their younger peers. Higher MVPA, but not sedentary behavior, was associated with better CRF. 
Conclusions: In all three settings, higher levels of MVPA were associated with higher CRF scores. Nevertheless, children living in the most urbanized setting (such as observed in ZA) were physically less active and had lower CRF than peers living in more rural areas (such as observed in $\mathrm{Cl}$ and TZ). Particularly for girls, urbanization might increase the risk for insufficient MVPA, which may have negative effects on their CRF, thus negatively influencing health and well-being at later age.

Keywords: accelerometry, Côte d'Ivoire, maximal oxygen uptake, sedentary behavior, South Africa, Tanzania, cardiorespiratory fitness

\section{INTRODUCTION}

Opportunities for children to engage in sport, physical activity (PA), and play are regarded as a fundamental human right by the World Health Organization (WHO) and the United Nations Educational, Scientific and Cultural Organization (UNESCO) (1). Regular PA-defined as any movement of the body, which is produced by the skeletal muscles and which requires energy expenditure (e.g., at school, during leisure time, for transport) (2)-helps to ensure optimal metabolic function and to reduce the risk of chronic degenerative diseases and premature death (3). Hence, the promotion of PA among children and adolescents is given high priority in high-income countries (HICs) (4), whereas low- and middle-income countries (LMICs) have paid less attention to this issue $(5,6)$. Currently, international PA recommendations suggest that children and adolescents should engage in at least $60 \mathrm{~min}$ of moderate-to-vigorous PA (MVPA) per day (7).

Meanwhile, the positive impact of PA on children's health and well-being is well-documented across various domains, including physical, physiological, developmental, mental, cognitive, and social health, as well as academic attainment $(8,9)$. While evidence is largely derived from research in HICs, recent studies from LMICs confirmed the positive relationships between PA and health. For instance, a study with primary schoolchildren living in marginalized settings in the Eastern Cape province of South Africa (ZA) showed that higher PA levels are associated with higher quality of life (10), better academic achievement (11), and more favorable cardiovascular health (12), independently of whether PA is assessed via self-report (13) or accelerometer

\footnotetext{
Abbreviations: BMI, Body mass index; CI, Côte d'Ivoire; CNESVS, Comité National d'Ethique des Sciences de la Vie et de la Santé; CRF, Cardiorespiratory fitness; CSRS, Centre Suisse de Recherches Scientifiques en Côte d'Ivoire; EKNZ, Ethikkommission Nordwest- und Zentralschweiz' in Switzerland; HAKSA, Healthy Active Kids South Africa; HICs, High income countries; ICAD, International Children's Accelerometry Database; IHI, Ifakara Health Institute; IRB, Institutional Review Board; ISRCTN, International Standardized Randomized Controlled Trial Number; LMICs, Low- and middle income countries; LPA, Light-intensity physical activity; (M)ANCOVA, (Multivariate) analyse of covariance; MPA, Moderate-intensity physical activity; MVPA, Moderate-to-vigorous physical activity; NIMR, National Institute for Medical Research; PA, Physical activity; TFDA, Tanzania Food and Drugs Authority; TV, Television; TZ, Tanzania; UNESCO, United Nations Educational, Scientific and Cultural Organization; $\mathrm{VO}_{2}$ max, Maximal oxygen uptake; $\mathrm{VO}_{2}$ peak, Peak oxygen uptake; VPA, Vigorous-intensity physical activity; WHO, World Health Organization; ZA, South Africa.
}

devices (14). Nevertheless, studies have also pointed toward decreasing levels of PA among children and adolescents (15). This is of particular concern, as prolonged sedentary behavior may have negative consequences for children's health (16).

In LMICs, a particularly strong decline of PA seems to occur among children living in urban settings (17). In a recent review of 298 population-based cross-sectional surveys, including 1.6 million participants, Guthold et al. (18) examined global trends in insufficient PA among youngsters aged 11-17 years. Their report suggests that globally, in 2016,81.0\% of youngsters did not engage in sufficient PA. Insufficient PA was more prevalent in girls $(84.7 \%)$ than boys $(77.6 \%)$. Similar findings were reported in a review that focused on youngsters aged 1317 years from LMICs (19), in which data from 49 countries were combined and included a total of 164,771 participants. This review showed that $<30 \%$ of the study population met current WHO recommendations, with boys being more likely to meet PA standards than girls. In sub-Saharan countries, the prevalence of sufficiently active youngsters varied between 8.2 and $25.6 \%(M=15 \%)$.

Observations of lower PA in girls than boys appear consistent across sub-Saharan Africa, and in both children and adolescents (17). As highlighted by Bénéfice and Ndiayene (20, p. 367), one contributing factor is that "in traditional subsistence populations, the workload must be shared among family members, and a strict division of tasks is present according to age and sex. Children and adolescents, especially girls, are frequently involved in daily agricultural or domestic tasks. Men are generally in charge of high-energy-demanding muscular tasks, while women and children are allotted time-consuming tasks."

With regard to age, a study showed that in children, the amount of MVPA peaks around school entry, and then starts to decline (21). Other studies, however, found that MVPA increases until the age of 12 years (22). Data from the International Children's Accelerometry Database (ICAD), including children aged between 3 and 18 years, revealed a decrease of $4.2 \%$ in total PA with each additional year of age (23). Based on a similar international cross-sectional database with 24,025 children aged 5-18 years, Corder et al. (24) observed a 6.9\% relative reduction in mean vigorous PA (VPA) with every year of age (corresponding to a reduction of $7.8 \mathrm{~min}$ ), with a stronger decline in girls $(10.7 \%)$ than in boys $(2.9 \%)$. For moderate PA (MPA), the reduction amounted to $6.0 \%$ (which corresponds to $22.8 \mathrm{~min}$, no sex differences reported). 
The assessment and interpretation of PA in children and adolescents is among the most challenging tasks in epidemiology (25). So far, self-reported PA questionnaires have been the preferred tool for global surveillance (18), but they might be susceptible to recall and response bias, have limited criterion validity, and can overestimate PA behaviors among young people (26). As a consequence, more objective measures, such as pedometers and accelerometers, are increasingly used. Accelerometers have particularly gained increasing popularity to assess habitual PA patterns in large studies because they can capture detailed and meaningful data over longer periods. Nevertheless, data on objectively measured PA levels among African primary schoolchildren are still scarce.

Despite the advantages, accelerometer application does imply some challenges: the devices are relatively expensive, including specialized software, while data collection and analyses are complex, time consuming, and permeated with compliance issues $(27,28)$. Hence, field-based measures of cardiorespiratory fitness (CRF) are a suitable alternative (29). CRF reflects the ability of the organism to deliver oxygen to the muscles and to utilize it for energy generation that supports muscle activity during exercise $(25,30)$. Peak oxygen uptake $\left(\mathrm{VO}_{2}\right.$ peak) or maximal oxygen uptake $\left(\mathrm{VO}_{2} \mathrm{max}\right)$ reflect the highest rate, at which oxygen can be consumed during exercise (31). Some researchers consider CRF to be a relatively stable reflection of past PA behavior, "similar to glycosylated hemoglobin, reflecting glucose control over a period of several months" [(29), p. 794].

CRF depends on a series of non-modifiable or relatively stable factors such as sex, age, growth, sexual maturation, and genetic influences. With regard to sex- and age-related differences, boys generally perform better in CRF tests than girls, by achieving higher estimated $\mathrm{VO}_{2}$ max levels (32), independent on whether CRF is expressed in absolute $(\mathrm{ml} / \mathrm{min})$ or body mass related terms $(\mathrm{ml} / \mathrm{kg} / \mathrm{min})(25)$. The same pattern has also been documented in children from sub-Saharan African countries (17). Nevertheless, sex differences remain relatively small until the age of 10-12 years, and then become markedly larger during adolescence (33).

Although $30-50 \%$ of CRF is determined by genetic factors, researchers assume that improvements in CRF can mainly be achieved through regular participation in PA (29). Hence, evidence suggests that trained children and adolescents have a higher $\mathrm{VO}_{2}$ peak than untrained peers (34). Among trained boys, $\mathrm{VO}_{2}$ peak values can reach levels of up to $60 \mathrm{ml} / \mathrm{min}$, and among girls $50 \mathrm{ml} / \mathrm{min}$ (30). A recent meta-analysis showed that CRF is associated with children's MVPA, independent of sedentary time (35). Nevertheless, this aspect has rarely been studied in African populations. One of the few studies to address this was a crosssectional study with 111,099 Kenyan adults (17-68 years), which yielded a significant relationship between CRF and habitual PA $(r=0.59)$ (36), yet, no such relationship was observed among Senegalese primary schoolchildren (20).

The purpose of this paper was (i) to describe and compare the PA behavior [sedentary behavior, light physical activity (LPA), MPA, VPA, and MVPA] and CRF of primary schoolchildren from three African countries [Côte d'Ivoire (CI), Tanzania (TZ), and $\mathrm{ZA}]$; (ii) to examine sex- and age-related differences; and (iii) to examine whether MVPA and CRF are similarly associated with each other in boys and girls.

\section{MATERIALS AND METHODS}

\section{Study Design}

In this paper, we present baseline data from the KaziAfya clusterrandomized controlled trial. In this trial, we intended to collect data at three distinct time points with primary schoolchildren from grades 1-4 from three African countries (CI, TZ, and ZA). According to the study protocol, data assessment occurred at baseline and then again at 9 and 21 months after baseline. In each participating school, we randomly assigned classes to one of four intervention conditions: (i) physical activity; (ii) multimicronutrient supplementation; (iii) physical activity plus multimicronutrient supplementation; and (iv) no intervention, thus serving as control. Details of the study have been presented elsewhere (37).

\section{Participants and Procedures}

Table 1 describes the settings and periods, in/during which the baseline data assessment took place. All schools were public. We first contacted school authorities before seeking contact to schools through the school principals. Schools were eligible for the study if facilities were available for the implementation of physical education lessons and if they did not engage in any other research project or clinical trial.

Before the start of the baseline data assessment, written informed consent was obtained from the parents/guardians of the children. Research assistants used an information sheet to explain the purpose and procedures of the study, the expected duration, potential risks and benefits, and any discomfort it may entail for the children. Additionally, all children provided oral assent before the start of the study. To be considered for data analyses, children had to attend grade 1-4; being no older than 12 years; not participating in other research projects or clinical trials; and not suffering from clinical conditions that prevented participation in PA, as determined by qualified medical personnel.

\section{Ethical Considerations}

In $\mathrm{CI}$, the study protocol was approved by the Institutional Review Board (IRB) of the Centre Suisse de Recherches Scientifiques en Côte d'Ivoire (CSRS) and the Comité National d'Ethique des Sciences de la Vie et de la Santé (CNESVS; reference number: 100-18/MSHP/CVESVS-km). In ZA, approval was granted by the research ethics committee of the Nelson Mandela University in Gqeberha (reference number: H18-HEA-HMS-006) and the Eastern Cape Departments of Education and Health. In TZ, the study protocol was approved by the responsible ethics committee at the Ifakara Health Institute (IHI-IRB; reference number: \# IHI/IRB/No 39-2018), the National Institute for Medical Research (NIMR; reference number: NIMR/HQ/R.8a/Vol. IX/3137), and the Tanzania Food and Drugs Authority (TFDA; reference number: TMDA0019/CTR/0016/05). Children who suffered from severe medical conditions and/or malnourishment (as 
TABLE 1 | Overview of the locations and settings, in which the study took place in each country.

\begin{tabular}{|c|c|c|c|}
\hline Country & Côte d'Ivoire (Cl) & South Africa (ZA) & Tanzania (TZ) \\
\hline Size of country $\left(\mathrm{km}^{2}\right)$ & $322,462 \mathrm{~km}^{2}$ & 1.22 million km² & $947,303 \mathrm{~km}^{2}$ \\
\hline Number of inhabitants in country & 26.45 million (2020) & 57.78 million (2018) & 56.31 million (2018) \\
\hline Study site & $\begin{array}{l}\text { The study was conducted in Taabo, } \\
\text { which is a typical small to medium } \\
\text { sized town located in the } \\
\text { south-central part of Côte d'Ivoire. } \\
\text { The Taabo site was chosen because } \\
\text { it houses a Primary Education } \\
\text { Inspectorate and a demographic and } \\
\text { health surveillance system that } \\
\text { includes } 13 \text { villages and more than } \\
100 \text { hamlets. }\end{array}$ & $\begin{array}{l}\text { The study was conducted in the } \\
\text { Gqeberha area, in Eastern Cape. } \\
\text { Four schools were selected from } \\
\text { Zwide, New Brighton, Gelvandale, } \\
\text { and Bethelsdorp. These areas are } \\
\text { classified as peri-urban areas. }\end{array}$ & $\begin{array}{l}\text { The study was conducted in } \\
\text { peri-urban settings in Ifakara town } \\
\text { council in the Kilombero district in } \\
\text { southern Tanzania. Four wards were } \\
\text { randomly selected within Ifakara } \\
\text { town; these were Kining'ina, } \\
\text { Katindiuka, Mlabani, and Kibaoni. }\end{array}$ \\
\hline Number of inhabitants in study site & $42,480(2014)$ & 967,677 (Gqeberha) & $\begin{array}{l}\text { The four wards have a population of } \\
\text { between } 10,000 \text { and } 20,000 \text { people } \\
\text { each, most of whom are subsistence } \\
\text { rice farmers. }\end{array}$ \\
\hline Number of primary schools at study site & $64(2017)$ & 103 (quintile three schools) & $\begin{array}{l}\text { Each ward has one public primary } \\
\text { school. }\end{array}$ \\
\hline Setting & Rural & Peri-urban & Peri-urban \\
\hline Description of living conditions & $\begin{array}{l}\text { The bulk of Taabo's economy relies } \\
\text { on agriculture, which employs } 90 \% \text { of } \\
\text { the population. It has two companies } \\
\text { in the agricultural sector and a } \\
\text { hydroelectric power station } \\
\text { (hydroelectric dam) with a total energy } \\
\text { production of } 550 \text { Mega Watt/hour } \\
\text { ( } 2 \% \text { of the national production). }\end{array}$ & $\begin{array}{l}\text { The schools are situated in historically } \\
\text { neglected, apartheid demarcated } \\
\text { Black African and colored areas that } \\
\text { have been adversely affected by high } \\
\text { unemployment rates and extreme } \\
\text { poverty. }\end{array}$ & $\begin{array}{l}\text { The majority of the residents of the } \\
\text { town are rice farmers, but they also } \\
\text { conduct small businesses, fishing and } \\
\text { animal husbandry. }\end{array}$ \\
\hline Number of schools taking part in study & 8 & 4 & 4 \\
\hline Number of classes involved in study & 32 & 41 & 16 \\
\hline Date of data assessment & October to December 2018 & January to March 2019 & July to August 2019 \\
\hline
\end{tabular}

diagnosed by a nurse, following national guidelines) were referred to local clinics. Ethical approval was also obtained from the "Ethikkommission Nordwest- und Zentralschweiz" in Switzerland (EKNZ; reference number: Req-2018-00608), and the study was registered in the ISRCTN registry (http://www. isrctn.com/ISRCTN29534081).

\section{Assessment of Physical Activity and Cardiorespiratory Fitness}

Light triaxial accelerometers (ActiGraph ${ }^{\circledR} \quad$ wGT3X-BT; Pensacola, United States of America) were used to objectively assess children's PA behavior during one regular school week. Previous studies have shown that these monitors are a reliable measure to assess PA levels (38). The children were instructed to wear the accelerometer on 7 consecutive days around the hip, except for activities in water. A sampling rate of $30 \mathrm{~Hz}$ was chosen. Raw files were analyzed with the ActiLife software (version 6.13.2). A day was considered valid if children wore the monitor for at least $8 \mathrm{~h}$ (39). Non-wear time was estimated with default settings of the Troiano et al. (40) algorithm. Only children with valid data on $\geq 4$ weekdays and $\geq 1$ weekend day were included (41). The applied cut-points were specifically defined for children to calculate indices for sedentary behavior, LPA, MPA, VPA, and an overall index for MVPA (42).
CRF was assessed with the $20 \mathrm{~m}$ shuttle run test (43), starting with a pace of $8.5 \mathrm{~km} / \mathrm{h}$. The speed was steadily increased by $0.5 \mathrm{~km} / \mathrm{h}$, following sound signals. The test was finished when children were no longer able to follow the speed of the sound signal twice in a row. The total number of fully completed $20 \mathrm{~m}$ laps was noted to predict $\mathrm{VO}_{2}$ max according to the equation put forward by Léger et al. (43). The $20 \mathrm{~m}$ shuttle run is a reliable and broadly validated field test to assess CRF among children (29).

\section{Statistical Analyses}

Descriptive statistics for all study variables are reported separately for each country (Table 2). Normality was tested via the Kolmogorov-Smirnov test. If severe non-normality was observed in one country (skewness and kurtosis values of $\geq|2|$ and/or $\geq|7|$, respectively) (44), values were log-transformed (natural $\log$ ) before calculating inferential statistics. Multi- and univariate analyses of covariance ([M]ANCOVAs) were done to examine differences in PA and CRF, between countries, boys and girls, and children with different age. Bonferroni post-hoc tests were used to examine differences between single countries. To examine whether MVPA is associated with CRF, we carried out mixed linear regression analyses (for the total samples in each country, and separately for boys and girls). Class membership was considered as a random intercept to account for the nested 
TABLE 2 | Descriptive statistics for the total sample, separately for children from Côte d'Ivoire (Cl), South Africa (ZA), and Tanzania (TZ).

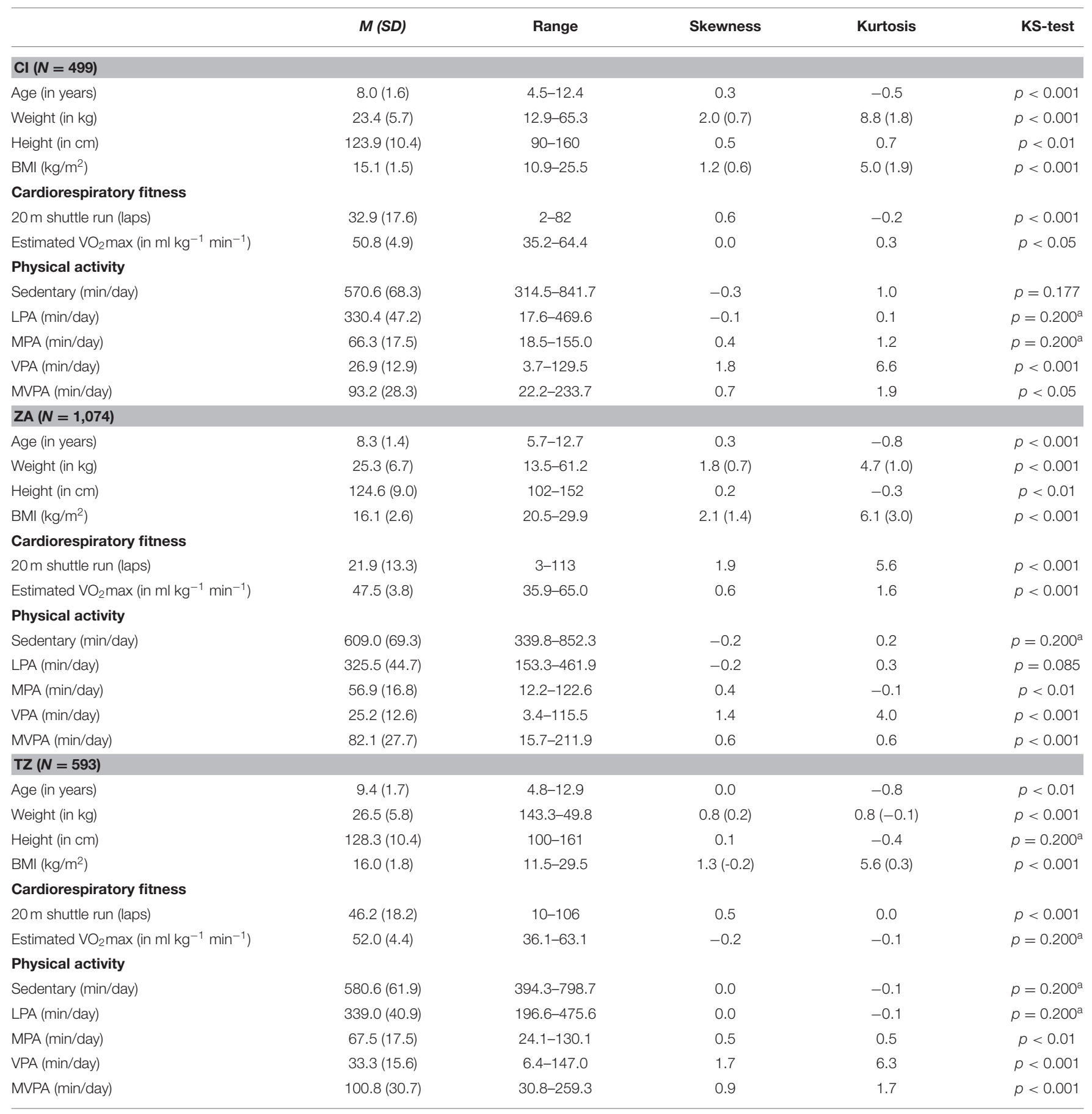

PA, physical activity; LPA, light-intensity physical activity; MPA, moderate-intensity physical activity; VPA, vigorous-intensity physical activity; MVPA, moderate-to-vigorous-intensity physical activity.

a Lower threshold of real significance.

nature of the data. Age, body mass index (BMI), sex, and accelerometer wear time were used as potential confounders. All statistical analyses were carried out with SPSS version 26 for Mac (IBM Corporation; Armonk, United States of America). The level of statistical significance was set at $p<0.05$ across all analyses.

\section{RESULTS}

\section{Sample Characteristics}

In CI, 499 children presented with complete data across all study variables (mean age: $8.0 \pm 1.6$ years, 252 boys, 247 girls). The mean $\mathrm{VO}_{2}$ max was $50.8 \pm 4.9 \mathrm{ml} \mathrm{kg}^{-1} \mathrm{~min}^{-1}$ and children 
engaged in $93.2 \pm 28.3 \mathrm{~min}$ of MVPA per day (Table 2). Most of the variables were not normally distributed; however, severe non-normality was only observed for weight, which was then logtransformed. In total, $89.6 \%$ of the children met current MVPA standards ( $\geq 60 \mathrm{~min} /$ day).

In $\mathrm{ZA}, 1,074$ children had complete data records (mean age: $8.3 \pm 1.4$ years, 545 boys, 529 girls). Mean $\mathrm{VO}_{2} \max$ was $47.5 \pm$ $3.8 \mathrm{ml} \mathrm{kg}^{-1} \mathrm{~min}^{-1}$ and mean MVPA was $82.1 \pm 27.7 \mathrm{~min} /$ day (Table 2). With the exception of sedentary behavior and LPA, none of the variables were normally distributed; severe nonnormality was only observed for BMI, which disappeared after log-transformation. In total, $76.9 \%$ of the children met current MVPA standards.

In TZ, 593 children had complete data records (mean age: $9.4 \pm 1.7$ years, 291 boys, 302 girls). The descriptive statistics show that mean $\mathrm{VO}_{2}$ max was $52.0 \pm 4.4 \mathrm{ml} \mathrm{kg}^{-1} \mathrm{~min}^{-1}$ and children engaged in 100.8 $\pm 30.7 \mathrm{~min}$ of MVPA per day (Table 2). Although most variables were not normally distributed, we did not observe severe non-normality in any of the study variables. In total, $93.8 \%$ of the children met MVPA standards.

\section{Between-Country Differences}

After controlling for sex, age, and BMI, MANCOVA pointed toward a significant between-country difference in CRF, WilksLambda: $F_{(4,4,318)}=176.7, p<0.001, \eta^{2}=0.141$. Univariate ANCOVAs showed that that there were significant differences between countries for laps completed in the $20 \mathrm{~m}$ shuttle run test, $F_{(2,2,160)}=372.4, p<0.001, \eta^{2}=0.256$, and estimated $\mathrm{VO}_{2} \max$, $F_{(2,2,160)}=380.1 p<0.001, \eta^{2}=0.260$. Bonferroni post-hoc tests revealed significant differences between all country-pairs $(p$ $<0.001)$. Children from TZ achieved the highest CRF levels, followed by peers from CI and ZA.

A similar pattern of findings was observed for accelerometerbased PA data. After controlling for sex, age, BMI, and accelerometer wear time, MANCOVA showed a significant main effect for country, Wilks-Lambda: $F_{(8,4,312)}=49.2, p<0.001, \eta^{2}$ $=0.084$. On the univariate level, ANCOVAs yielded significant between-country differences for sedentary behavior, $F_{(2,2,159)}$ $=95.4, p<0.001, \eta^{2}=0.081, \mathrm{LPA}, F_{(2,2,159)}=51.6, p<$ $0.001, \eta^{2}=0.046, \mathrm{MPA}, F_{(2,2,159)}=105.1, p<0.001, \eta^{2}$ $=0.089$, and VPA, $F_{(2,2,159)}=61.3, p<0.001, \eta^{2}=0.054$. A significant difference was also found for MVPA, $F_{(2,2,159)}$ $=87.1, p<0.001, \eta^{2}=0.075$. With a few exceptions, the Bonferroni post-hoc tests showed significant differences between all country-pairs $(p<0.05)$. The only exceptions were that no significant differences occurred in LPA between children from CI and ZA $(p=0.133)$ and in MPA between children from CI and TZ $(p=0.626)$. Children in ZA had the highest levels of sedentary behavior, followed by peers from $\mathrm{TZ}$ and CI. Across all PA indicators (LPA, MPA, VPA, and MVPA), the highest values were seen in children from TZ, followed by peers from CI and ZA.

Significant between-country differences were also found in the portion of children who met MVPA standards, $\chi_{(2,2,166)}^{2}=95.4, p$ $<0.001$. Pair-wise comparisons showed that the portion differed between children from CI and ZA, $\chi_{(1,1,573)}^{2}=35.4, p<0.001$,
$\mathrm{TZ}$ and $\mathrm{ZA}, \chi_{(1,1,667)}^{2}=76.3, p<0.001$, and $\mathrm{CI}$ and TZ, $\chi_{(1,1,092)}^{2}$ $=6.3, p<0.01$, with the highest proportion of children meeting MVPA standards found in study participants from TZ, followed by peers from $\mathrm{CI}$ and $\mathrm{ZA}$.

\section{Sex Differences}

After controlling for age and BMI, MANCOVAs showed significant between-sex differences for CRF in children from ZA, Wilks-Lambda: $F_{(2,1,069)}=7.1, p<0.01, \eta^{2}=0.013$, and TZ, Wilks-Lambda: $F_{(2,588)}=63.0, p<0.001, \eta^{2}=0.176$. By contrast, no significant between-sex differences were found in children from CI, Wilks-Lambda: $F_{(2,494)}=1.7, p=0.177, \eta^{2}$ $=0.007$. In children from $\mathrm{ZA}$ and $\mathrm{TZ}$, boys reached higher $\mathrm{CRF}$ scores than girls in the univariate analyses (Table 3).

After controlling for age, BMI and wear time, MANCOVAs yielded significant sex differences in PA behavior in children from CI, Wilks-Lambda: $F_{(4,492)}=17.8, p<0.001, \eta^{2}=0.098$, ZA, Wilks-Lambda: $F_{(4,1,066)}=73.0, p<0.001, \eta^{2}=0.215$, and TZ, Wilks-Lambda: $F_{(4,585)}=31.6, p<0.001, \eta^{2}=0.178$. Based on the univariate analyses (Table 3 ), girls reported more time for sedentary behavior, with the main effect of sex being particularly strong among children from ZA (11.2\% of explained variance). With regard to MPA, VPA, and MVPA, the same pattern of results was found across all countries, with boys being more active than girls. For LPA, a significant difference was only found in children from ZA, with boys having higher scores than girls. Regarding MVPA, a particularly large main effect of sex was found in children from ZA (21.2\% of explained variance), with boys engaging in $\sim 25 \mathrm{~min}$ of MVPA more on average than girls.

In CI, the number of boys (91.7\%) and girls (87.4\%) who met the current MVPA standards was similarly high, $\chi_{(1,499)}^{2}=2.4, p$ $=0.123$. Likewise, no significant differences were found between boys (95.5\%) and girls (92.0\%) from TZ, $\chi_{(1,593)}^{2}=3.1, p=0.078$. In $\mathrm{ZA}$, however, boys $(91.0 \%)$ were significantly more likely to engage in sufficient MVPA than girls $(62.4 \%), \chi_{(1,1,074)}^{2}=123.9$, $p<0.001$.

\section{Age-Related Differences}

After controlling for sex and BMI, MANCOVAs showed that CRF differed in relation to age among children from CI, WilksLambda: $F_{(8,930)}=202.9, p<0.001, \eta^{2}=0.636$, ZA, WilksLambda: $F_{(8,2,080)}=7.1, p<0.001, \eta^{2}=0.555$, and TZ, WilksLambda: $F_{(12,1,166)}=223.3, p<0.001, \eta^{2}=0.697$. As shown in Table 4, the univariate analyses revealed that the number of completed laps in the $20 \mathrm{~m}$ shuttle run increased from the age of 6 until the age of 10 years in all countries (total increase in $\mathrm{CI}:+23.9 \%$, $\mathrm{ZA}:+77.7 \%$, and $\mathrm{TZ}:+29.9 \%)$. By contrast, estimated $\mathrm{VO}_{2}$ max decreased steadily from the age of 6 to the age of 10 years (total decrease in CI: $-9.2 \%$, ZA: $-7.6 \%$, and TZ: $-7.2 \%)$. Nevertheless, in children from $\mathrm{TZ}, \mathrm{VO}_{2} \mathrm{max}$ reached a plateau and no longer decreased after the age of 10 years (see Figure 1).

After controlling for age, BMI, and wear time, MANCOVAs yielded significant age-related differences in PA behavior in children from CI, Wilks-Lambda: $F_{(16,1,412)}=5.7, p<0.001, \eta^{2}$ $=0.047$, ZA, Wilks-Lambda: $F_{(16,3,169)}=6.7, p<0.001, \eta^{2}=$ 
TABLE 3 | Descriptive statistics for boys and girls, separately for children from Côte d'Ivoire (Cl), South Africa (ZA), and Tanzania (TZ).

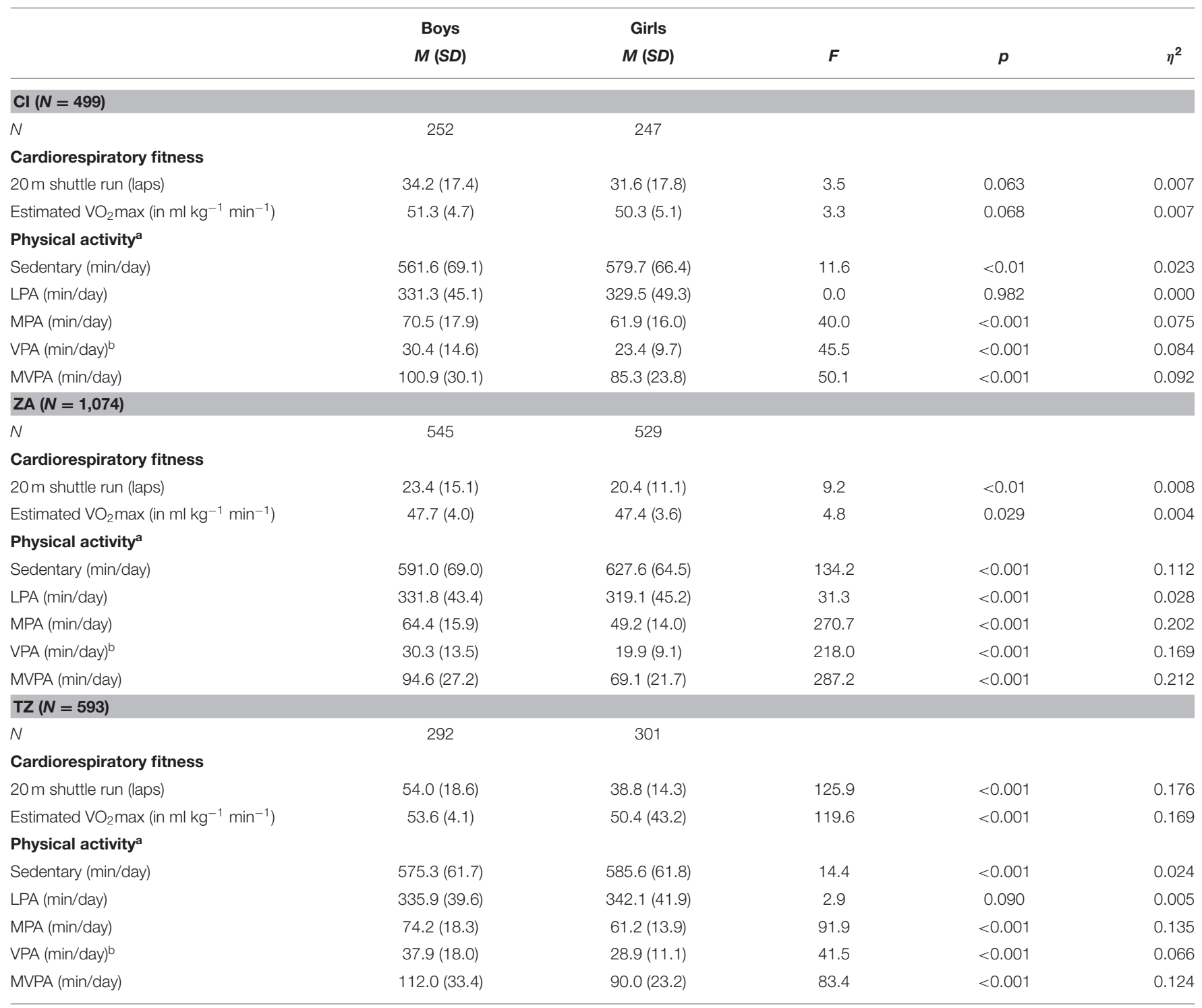

PA, physical activity; LPA, light-intensity physical activity; MPA, moderate-intensity physical activity; VPA, vigorous-intensity physical activity; MVPA, moderate-to-vigorous physical activity. (M)ANCOVAs are controlled for age and BMI (log transformed).

${ }^{a}$ For all physical activity outcomes, wear time was considered as a covariate.

bIf VPA was examined as an outcome variable, log-transformed scores were used.

0.025, and TZ, Wilks-Lambda: $F_{(24,2,025)}=4.9, p=0.001, \eta^{2}=$ 0.048. More specifically, the univariate analyses (Table 4) showed that sedentary behavior significantly increased in all countries from the age of $6-10$ years (total increase in CI: $+8.5 \%$, ZA: $+5.2 \%$, and TZ: $+6.6 \%$; see Figure 1). However, older children had higher MVPA scores than younger peers, a finding that was observed across all countries (total increase from age 6 to 10 years in CI: $+12.8 \%$, ZA: $+3.7 \%$, and TZ: $+8.8 \%$; see Figure 1 ).

Regarding the proportion of children who met MVPA standards, we did not observe significant age-related differences in any of the countries $\left[\mathrm{CI}, \chi_{(4,473)}^{2}=8.7, p=0.68, \mathrm{ZA}, \chi_{(4,1,048)}^{2}\right.$ $=3.9, p=0.415$, and TZ, $\left.\chi_{(6,593)}^{2}=8.2, p=0.223\right]$.

\section{Association Between Physical Activity and Cardiorespiratory Fitness}

Table 5 shows the results of the mixed linear regression models, first for the total sample in each country, then separately for girls and boys. In Table 5, sedentary behavior and MVPA are used as independent predictors. In the total sample, age was negatively associated with estimated $\mathrm{VO}_{2} \mathrm{max}$ in all countries. In children from ZA and TZ, higher BMI scores were associated with lower $\mathrm{VO}_{2} \max$. Moreover, sex differences were confirmed in the regression models in TZ children. A statistically significant (positive) relationship was found between MVPA and $\mathrm{VO}_{2} \max$ in children from $\mathrm{CI}(B=0.03, p<0.05,95 \%$ confidence interval 
TABLE 4 | Descriptive statistics for children with different years of age, separately for children from Côte d'Ivoire (Cl), South Africa (ZA), and Tanzania (TZ).

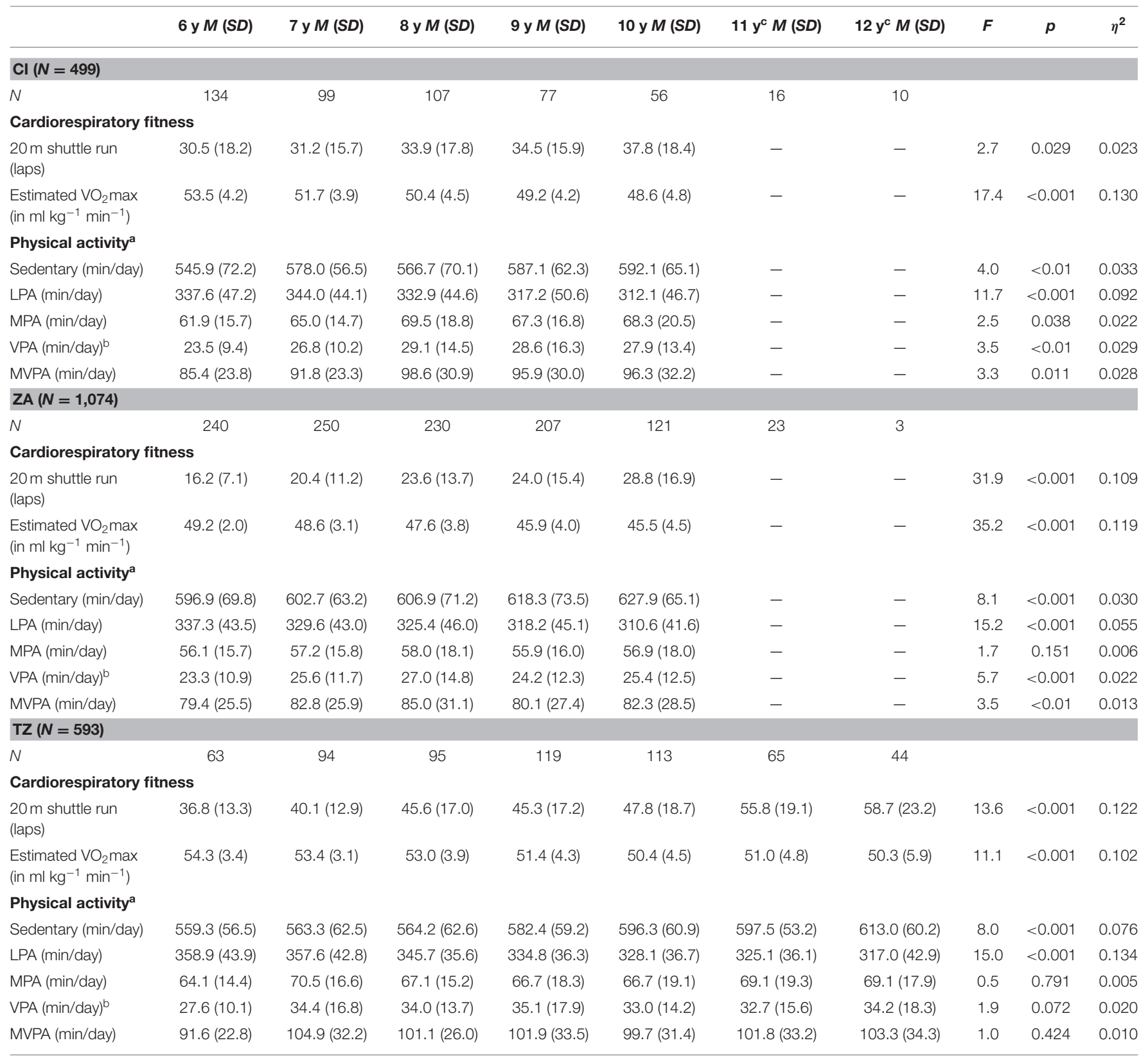

PA, physical activity; LPA, light-intensity physical activity; MPA, moderate-intensity physical activity; VPA, vigorous-intensity physical activity; MVPA, moderate-to-vigorous physical activity. (M)ANCOVAs are controlled for sex and BMI (log transformed).

${ }^{a}$ For all physical activity outcomes, wear time was considered as a covariate.

I If VPA was examined as an outcome variable, log-transformed scores were used.

${ }^{c}$ In the (M)ANCOVAs, 11- and 12-year-old children were only considered in the TZ sample, because in the samples from $\mathrm{Cl}$ the number of children aged 11 or 12 years were low ( $\mathrm{N} \leq 25$ children per year of age category).

$=0.01-0.05), \mathrm{ZA}(B=0.04, p<0.001,95 \%$ confidence interval $=$ $0.02-0.05)$; and TZ $(B=0.03, p<0.01,95 \%$ confidence interval $=0.01-0.04)$. Table 5 further shows that whereas higher levels of MVPA were consistently associated with higher $\mathrm{VO}_{2} \max$ in girls from all three countries, in boys, a significant relationship ( $p$ $<0.001$ ) was only found in ZA schoolchildren, although results pointed to the same direction in children from CI and TZ.
Table 6 makes a further distinction between LPA, MPA, and VPA in the prediction of CRF (in addition to sedentary behavior). In children from $\mathrm{CI}$ and $\mathrm{TZ}$, a significant association with $\mathrm{VO}_{2}$ max was observed for VPA (CI: $B=0.05, p<0.05$, $95 \%$ confidence interval $=0.01-0.10$; TZ: $B=0.05, p<0.01$, $95 \%$ confidence interval $=0.01-0.08$ ), but not for LPA and MPA. Nevertheless, this relationship only existed in girls (see 


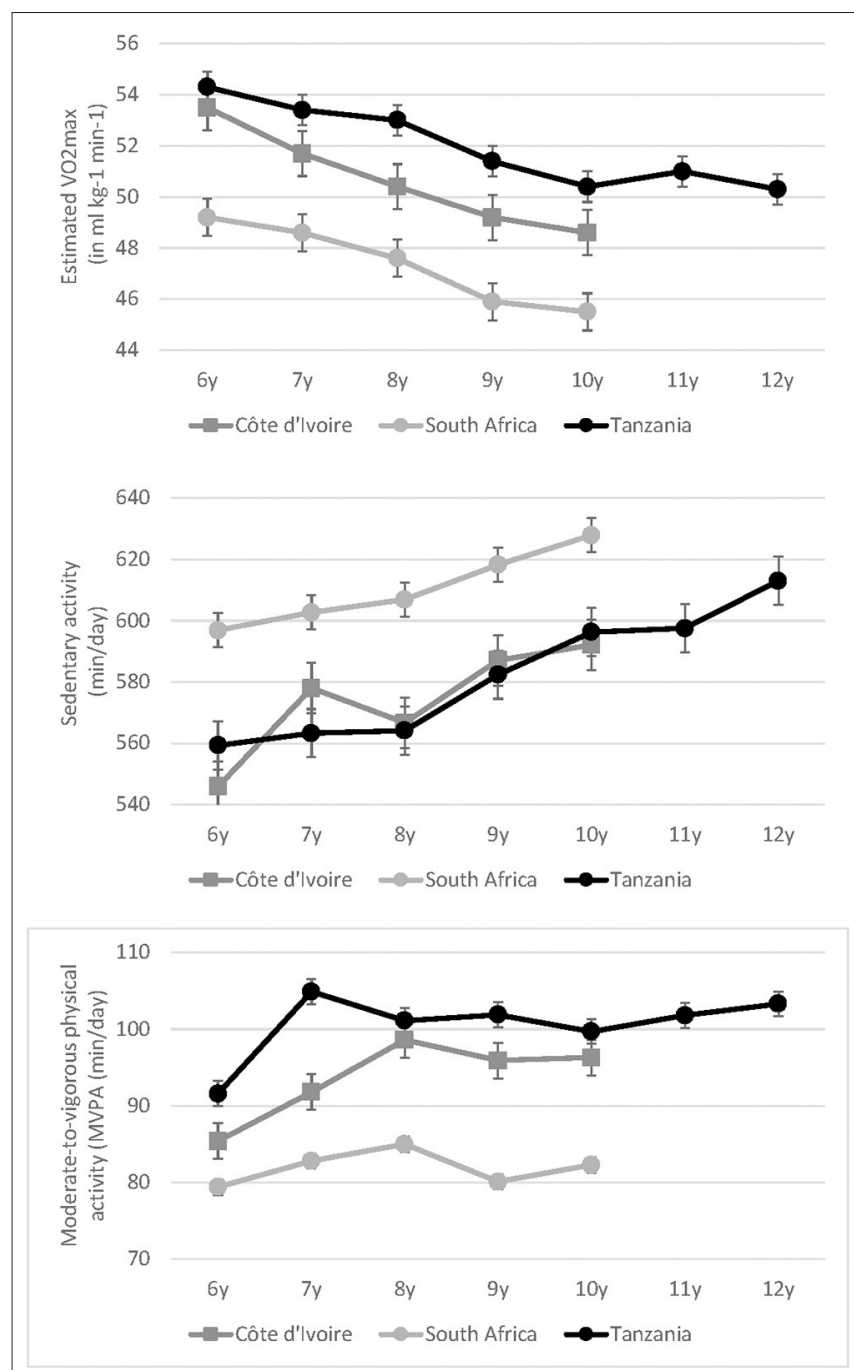

Error bars represent standard error.

FIGURE 1 | Estimated $\mathrm{VO}_{2}$ max and moderate-to-vigorous physical activity in children with different years of age, separately for children from Côte d'Ivoire, South Africa, and Tanzania.

scatterplots in Figure 2), whereas among boys no significant association between VPA and CRF occurred. In children from ZA, only MPA (but not LPA and VPA) was associated with $\mathrm{VO}_{2}$ max. This association was found both in girls $(B=0.04, p<$ $0.05,95 \%$ confidence interval $=0.01-0.07)$ and boys $(B=0.05, p$ $<0.01,95 \%$ confidence interval $=0.01-0.08$ ) (scatterplots shown in Figure 3).

\section{DISCUSSION}

The key findings of this study are that across the three African countries, most children met current MVPA recommendations and achieved relatively high CRF levels. Between-country comparisons revealed that children from $\mathrm{TZ}$ had the highest CRF and MVPA levels, followed by children from CI and peers from ZA. Boys had consistently higher PA levels than girls, whereas girls engaged in more sedentary behavior than boys. In two countries (ZA and TZ), boys also had higher CRF levels than girls. Absolute performance in a $20 \mathrm{~m}$ shuttle run (completed laps) increased with age, but estimated $\mathrm{VO}_{2} \max$ was decreasing with age. Both sedentary behavior and time spent in MVPA were higher among older children compared to their younger peers. MVPA was (positively) associated with estimated $\mathrm{VO}_{2} \max$ in the three study countries, whereas sedentary behavior was not.

With the present paper, we address four specific objectives. Firstly, we gained a deeper understanding of PA behavior and CRF of primary schoolchildren from three African countries. Our findings are at odds with previous reports showing that in sub-Saharan Africa, the majority of young people fail to meet MVPA standards $(18,19)$. However, previous reports focused on older children and adolescents ( $\geq 11$ years) and relied on self-reports, whereas in our study, we examined younger, preadolescent children ( $\leq 12$ years) and used accelerometer devices to objectively assess PA. This approach provides new insights into children's actual PA levels from African countries, and thus fills an important gap, as only few studies used accelerometer devices thus far (14). The fact that in our study the lowest PA levels were found among children from ZA (living in the most urbanized setting) was not a surprise, given that in LMICs, PA levels have more strongly declined in urban settings compared to rural settings (17), where schoolchildren often still walk relatively long distances to and from school. Researchers have emphasized that living in urban settings might significantly limit the opportunities for children to engage in regular and sufficient PA (45). Contributing factors are safety concerns that make it difficult for children to walk to schools or to parks, financial constraints that limit parents' possibilities to let their children participate in organized sport activities, general lack of sport facilities, and lacking facilities and equipment at schools (46).

With regard to children's CRF, Ruiz et al. (47) concluded that the CRF cut-points to avoid cardiovascular disease risk are $41.8 \mathrm{ml} \mathrm{kg}^{-1} \mathrm{~min}^{-1}$ for boys and $34.6 \mathrm{ml} \mathrm{kg}^{-1} \mathrm{~min}^{-1}$ for girls. In our study, the mean scores ranged from 47.7 to $53.6 \mathrm{ml} \mathrm{kg}^{-1} \mathrm{~min}^{-1}$ in boys and from 47.4 to $50.4 \mathrm{ml} \mathrm{kg}^{-1}$ $\min ^{-1}$ in girls, which highlights that CRF was relatively high in the present sample. Studies have pointed toward considerable between-country difference in the $20 \mathrm{~m}$ shuttle run test, which might be reflective of variations in the socioeconomic, cultural, and political circumstances in the different countries $(33,48)$. Lang et al. (48) synthesized studies on shuttle run performance from 50 countries with children and adolescents aged 9-17 years $(1,142,026$ participants). The review showed that best performances in the $20 \mathrm{~m}$ shuttle run were observed among youth from TZ (97th percentile rank). Performances of children and adolescents from CI were still relatively good (75th percentile rank), whereas those of youth from ZA were average (54th percentile rank), ranking similarly as countries like Spain or Switzerland.

The second objective of our paper was to examine whether PA and CRF differ between boys and girls. The findings of the present study accord well with previous investigations (17), indicating 
TABLE 5 | Association between children's physical activity and cardiorespiratory fitness in Côte d'Ivoire (CI), South Africa (ZA), and Tanzania (TZ).

\begin{tabular}{|c|c|c|c|c|c|c|}
\hline \multicolumn{7}{|c|}{ Total sample } \\
\hline & \multicolumn{2}{|r|}{$\mathrm{Cl}(N=499)$} & \multicolumn{2}{|c|}{$\mathrm{ZA}(N=1,074)$} & \multicolumn{2}{|r|}{$\mathrm{TZ}(N=593)$} \\
\hline & $B$ & $95 \%$ confidence interval & $B$ & $95 \%$ confidence interval & B & $95 \%$ confidence interval \\
\hline Age & $-1.43^{\star \star \star}$ & -1.70 to -1.16 & $-1.06^{\star \star \star}$ & -1.21 to -0.91 & $-0.77^{\star \star \star}$ & -0.97 to -0.59 \\
\hline BMI (log) & -7.71 & -17.34 to 1.92 & $-10.81^{\star \star \star}$ & -14.08 to -7.55 & $-11.29^{\star \star}$ & -17.85 to -4.72 \\
\hline Wear time & -0.01 & -0.01 to 0.01 & -0.00 & -0.01 to 0.00 & 0.00 & -0.01 to 0.01 \\
\hline Sedentary activity & 0.01 & -0.01 to 0.02 & 0.00 & -0.01 to 0.01 & 0.00 & -0.01 to 0.01 \\
\hline MVPA & $0.03^{\star}$ & 0.01 to 0.05 & $0.04^{\star \star \star}$ & 0.02 to 0.05 & $0.03^{\star \star}$ & 0.01 to 0.04 \\
\hline
\end{tabular}

Girls

\begin{tabular}{|c|c|c|c|c|c|c|}
\hline & \multicolumn{6}{|c|}{ Prediction of estimated $\mathrm{VO}_{2}$ max with MVPA } \\
\hline & $B$ & $95 \%$ confidence interval & $B$ & $95 \%$ confidence interval & $B$ & $95 \%$ confidence interval \\
\hline Age & $-1.48^{\star \star \star}$ & -1.88 to 1.09 & $-1.29^{\star \star \star}$ & -1.47 to -1.08 & $-1.19^{\star \star \star}$ & -1.45 to -0.92 \\
\hline BMI (log) & -10.39 & -22.85 to 2.07 & $-10.92^{\star \star \star}$ & -14.80 to -7.04 & -6.74 & -15.08 to 1.61 \\
\hline MVPA & $0.04^{\star}$ & 0.00 to 0.07 & $0.04^{\star \star \star}$ & 0.02 to 0.05 & $0.04^{\star \star \star}$ & 0.02 to 0.07 \\
\hline
\end{tabular}

Boys

\begin{tabular}{|c|c|c|c|c|c|c|}
\hline & \multicolumn{6}{|c|}{ Prediction of estimated $\mathrm{VO}_{2} \max$ with MVPA } \\
\hline & \multicolumn{2}{|r|}{$\mathrm{Cl}(N=252)$} & \multicolumn{2}{|r|}{$\mathrm{ZA}(N=545)$} & \multicolumn{2}{|c|}{ TZ $(N=292)$} \\
\hline & $B$ & $95 \%$ confidence interval & $B$ & $95 \%$ confidence interval & $B$ & $95 \%$ confidence interval \\
\hline Age & $-1.35^{\star \star \star}$ & -1.73 to -0.97 & $-0.88^{\star \star \star}$ & -1.11 to -0.66 & $-0.39^{\star \star}$ & -0.08 to -0.11 \\
\hline BMl (log) & -2.19 & -18.12 to 13.75 & $-10.95^{\star \star \star}$ & -16.49 to -5.41 & $-13.63^{*}$ & -23.95 to -3.31 \\
\hline Wear time & -0.01 & -0.02 to 0.01 & 0.00 & -0.01 to 0.01 & 0.00 & -0.01 to 0.02 \\
\hline Sedentary activity & 0.00 & -0.01 to 0.02 & 0.00 & -0.1 to 0.01 & -0.01 & -0.02 to 0.01 \\
\hline MVPA & 0.02 & -0.01 to 0.05 & $0.03^{\star \star \star}$ & 0.02 to 0.05 & 0.02 & -0.01 to 0.04 \\
\hline
\end{tabular}

MVPA, moderate-to-vigorous physical activity.

${ }^{*} p<0.05 .{ }^{* *} p<0.01 .{ }^{* \star *} p<0.001$.

that boys engage in more MVPA than girls. However, only in the ZA sample, a large gap between the two sexes was observed, with significantly fewer girls meeting MVPA standards than their male peers. This observation might indicate that urbanization and the changing life styles increase sex differences in PA. Adebusoye et al. [(49), p. 554] argued that urban development in Africa might reduce the number of conducive spaces for outdoor PA, which might be even less accessible for girls. Given that the highest population growth (and especially growth in urban areas) is expected over the next few decades in Africa and Asia (50), it is important to understand the factors that influence children's $\mathrm{PA}$ behaviors in these regions to create effective interventions to prevent a decline in PA (51). In this respect, in urbanized settings, girls constitute a special target group as they are more likely to engage in insufficient MVPA.
Our findings across all three countries further corroborate that boys reach higher CRF levels than girls $(17,25,32)$. However, these differences were negligible in younger children from ZA and CI, a finding that confirms previous research (33). Age might also explain why the observed sex differences were larger among children from TZ, as the mean age was higher among children from $\mathrm{TZ}$ compared to peers from the other participating countries (this is due to the different average age at the start of school). Researchers have suggested that higher $\mathrm{VO}_{2}$ peak scores are largely due to greater stroke volume in boys (52). Some researchers have further claimed that differences in cardiac size and cardiac function might be additional contributing factors (53). However, a study with prepubertal children using thoratic bioimpedance and cardiac magnetic resonance imaging showed that $\mathrm{VO}_{2}$ peak did not depend on maximal stroke volume or 
TABLE 6 | Association between physical activities with different intensities and children's cardiorespiratory fitness in Côte d'Ivoire (Cl), South Africa (ZA), and Tanzania (TZ).

Total sample

\begin{tabular}{|c|c|c|c|c|c|c|}
\hline \multicolumn{7}{|c|}{ Total sample } \\
\hline & \multicolumn{6}{|c|}{ Prediction of estimated $\mathrm{VO}_{2}$ max with MVPA } \\
\hline & \multicolumn{2}{|r|}{$\mathrm{Cl}(N=499)$} & \multicolumn{2}{|c|}{$\mathrm{ZA}(N=1,074)$} & \multicolumn{2}{|c|}{$\mathrm{TZ}(N=593)$} \\
\hline & $B$ & $95 \%$ confidence interval & $B$ & $95 \%$ confidence interval & $B$ & $95 \%$ confidence interval \\
\hline Age & $-1.40^{\star \star \star}$ & -1.67 to -1.12 & $-1.07^{\star \star \star}$ & -1.21 to -0.92 & $-0.76^{\star \star \star}$ & -0.96 to -0.56 \\
\hline Wear time ${ }^{a}$ & - & - & - & - & - & - \\
\hline Sedentary activity & 0.00 & -0.01 to 0.01 & 0.00 & -0.01 to 0.01 & 0.00 & -0.01 to 0.01 \\
\hline LPA & -0.00 & -0.01 to 0.01 & 0.00 & -0.01 to 0.01 & 0.00 & -0.01 to 0.01 \\
\hline MPA & -0.01 & -0.05 to 0.03 & $0.04^{\star \star \star}$ & 0.02 to 0.07 & 0.01 & -0.02 to 0.04 \\
\hline VPA & $0.05^{\star}$ & 0.01 to 0.10 & 0.02 & -0.01 to 0.05 & $0.05^{\star \star}$ & 0.01 to 0.08 \\
\hline
\end{tabular}

Girls

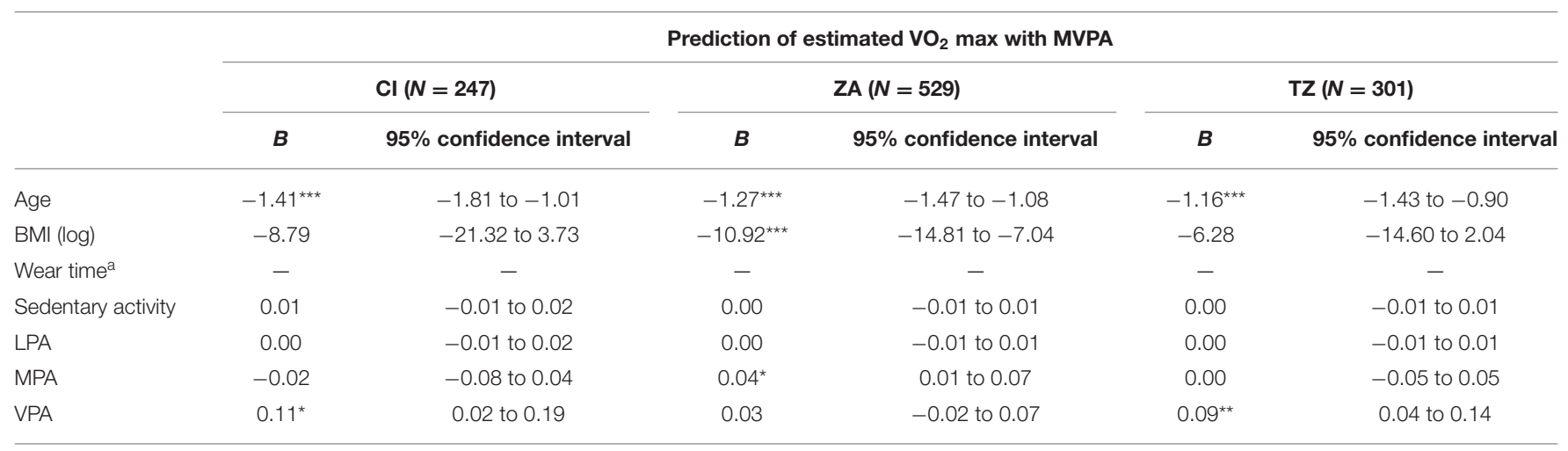

Boys

\begin{tabular}{|c|c|c|c|c|c|c|}
\hline & \multicolumn{6}{|c|}{ Prediction of estimated $\mathrm{VO}_{2}$ max with MVPA } \\
\hline & $B$ & $95 \%$ confidence interval & $B$ & $95 \%$ confidence interval & $B$ & $95 \%$ confidence interval \\
\hline Age & $-1.32^{\star \star \star}$ & -1.71 to -0.94 & $-0.89^{\star \star \star}$ & -1.11 to -0.67 & $-0.38^{* \star}$ & -0.67 to -0.10 \\
\hline BMl (log) & -2.02 & -17.97 to 13.94 & $-11.08^{\star \star \star}$ & -16.63 to -5.53 & $-13.31^{\star}$ & -23.68 to -2.95 \\
\hline LPA & 0.00 & -0.02 to 0.01 & -0.01 & -0.01 to 0.00 & 0.01 & -0.01 to 0.02 \\
\hline MPA & -0.01 & -0.06 to 0.05 & $0.05^{\star \star}$ & 0.01 to 0.08 & 0.00 & -0.04 to 0.04 \\
\hline VPA & 0.03 & -0.02 to 0.09 & 0.02 & -0.02 to 0.05 & 0.03 & -0.01 to 0.07 \\
\hline
\end{tabular}

LPA, light physical activity; MPA, moderate physical activity; VPA, vigorous physical activity.

a Wear time was not included as a covariate because wear time corresponds to the sum of sedentary activity, LPA, MPA, and VPA.

${ }^{*} p<0.05 .{ }^{* *} p<0.01 .{ }^{* \star *} p<0.001$.

resting heart size, but seemed to depend on children's maximal arterio-venous oxygen differences. Other researchers claimed that sex differences in $\mathrm{VO}_{2}$ peak might be a result of poorer matching of muscle oxygen delivery to oxygen utilization in girls, while others have suggested that the differences might be due to the fact that boys are more physically active (54).

The third objective of our research was to determine whether $\mathrm{CRF}$ and PA differ between children according to age. In our study, sedentary behavior and MVPA were higher in older children compared to their younger peers. This is in line with previous studies showing that MVPA peaks around the age of 12 years (22). From a public health perspective, it is problematic that sedentary behavior increases with age. For instance, in ZA, recent Healthy Active Kids South Africa (HAKSA) report cards reported that many children and adolescents engage in very high levels of sedentary behavior $(55,56)$. On average, children watched almost 


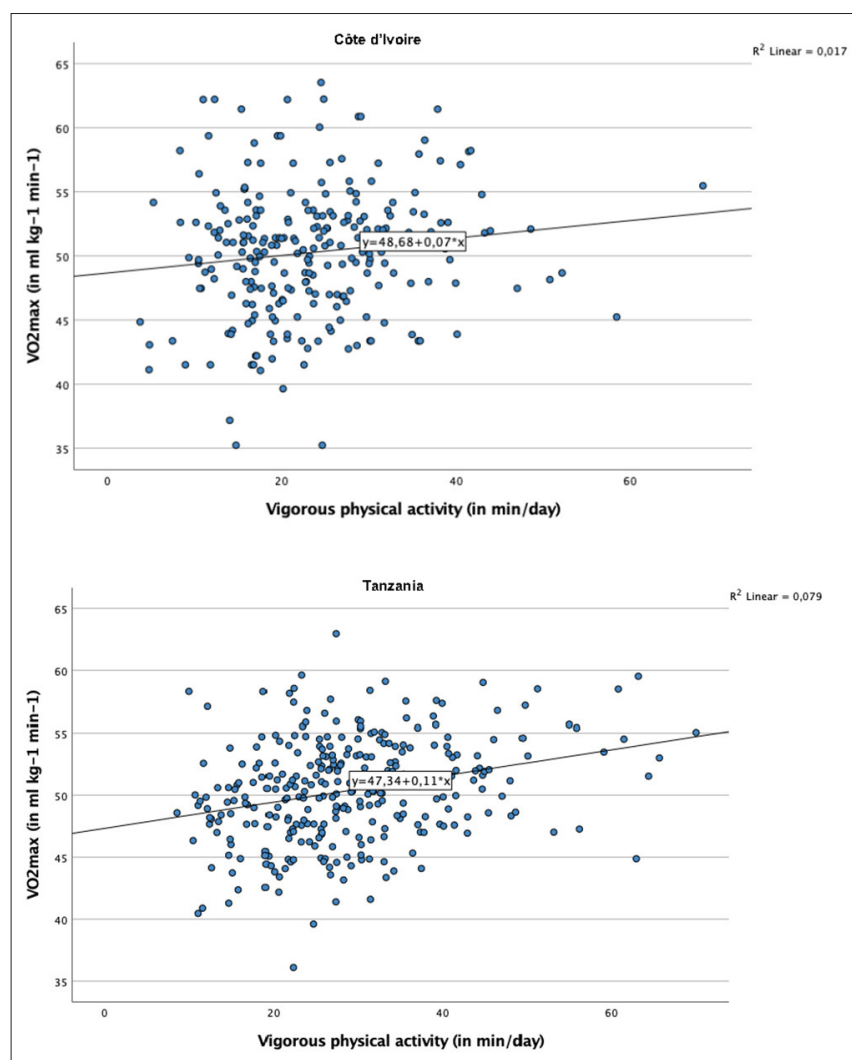

FIGURE 2 | Scatter plot with regression line representing the association between vigorous physical activity and cardiorespiratory fitness, for girls from Côte d'Ivoire and Tanzania.

$3 \mathrm{~h}$ of TV per day, with $31 \%$ of girls and $25 \%$ of boys watching TV more than $5 \mathrm{~h}$ during a normal school day (57).

Our results conflict with prior laboratory-based research showing that $\mathrm{VO}_{2}$ peak almost linearly increases in children between the age of 8 and 14 years (30). Nevertheless, our results support data from a cross-sectional survey with 156 schoolchildren aged 7-15 years from $\mathrm{CI}$, in which $\mathrm{VO}_{2}$ max decreased with age (32). The reason for these diverging results can probably be attributed to methodological issues. For instance, Armstrong and Welsman (58) warned against an overinterpretation of CRF scores derived from the $20 \mathrm{~m}$ shuttle run test. First, they argued that expressing $\mathrm{VO}_{2}$ peak in relation to age might be problematic, as peak oxygen uptake increases in accordance with morphological and physiological changes associated with growth and maturation and as there are substantial inter-individual differences with regard to the timing and tempo of these changes. Moreover, limited common variance was observed between performances in the $20 \mathrm{~m}$ shuttle run test and rigorously determined peak oxygen uptake in the laboratory among 11- to 14-year-old British schoolchildren (59). On the other hand, the $20 \mathrm{~m}$ shuttle run test is currently regarded as the most adequate field-based measure of CRF in children and youth due to its low costs, simplicity (no need for specialized human resources, easily interpretable results), and ability to assess large

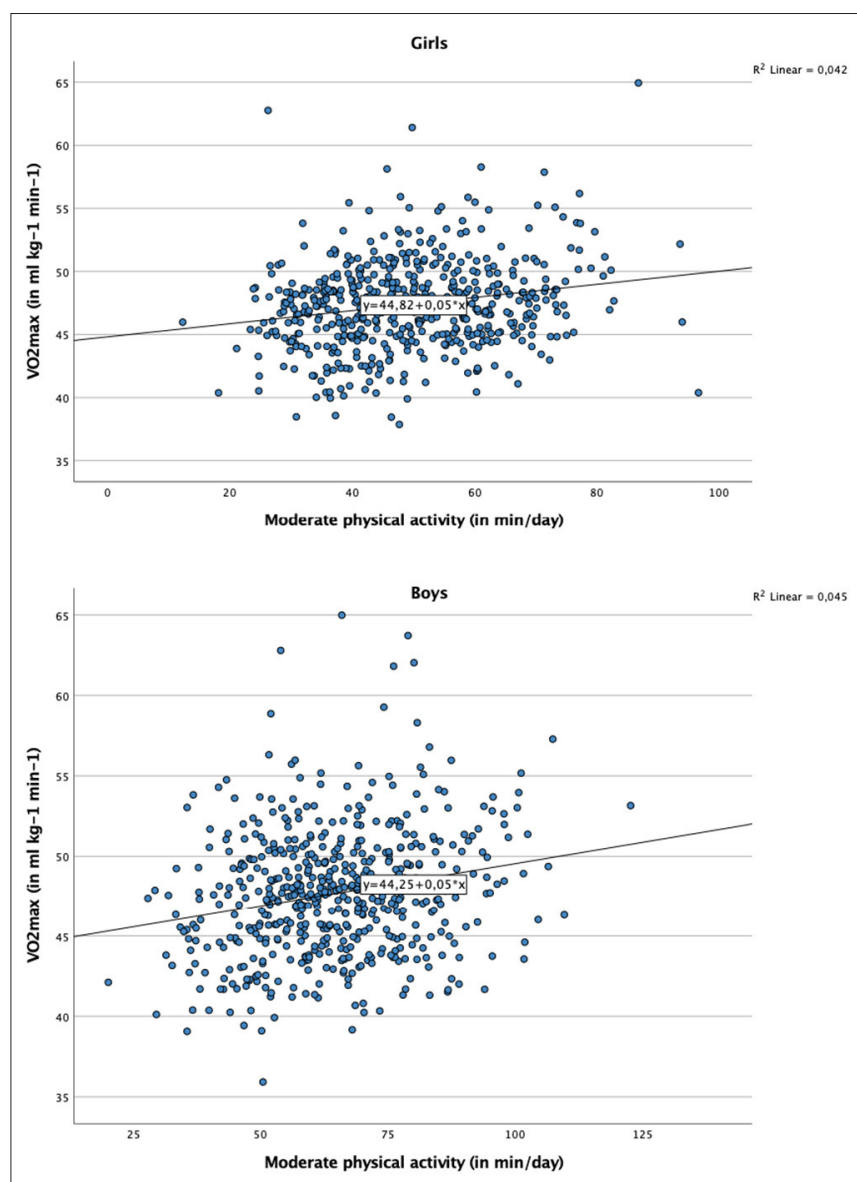

FIGURE 3 | Scatter plot with regression line representing the association between moderate physical activity and cardiorespiratory fitness, for girls and boys from South Africa.

groups of participants at the same time $(48,60)$. Moreover, this test proved to be a relevant marker of children's current (61) and future cardiovascular health (62).

The fourth objective of our study was to investigate whether MVPA is associated with CRF among schoolchildren. Our findings support this notion, which is in line with a recent metaanalysis, showing that irrespective of time spent in sedentary activities, CRF and MVPA are positively associated in children (35). Our study also corroborates field-based studies in which a significant association was found between objectively assessed MVPA and children's CRF $(63,64)$. The findings of our mixed linear regression analyses show that the mean $\mathrm{VO}_{2}$ max score increased by $0.03-0.04 \mathrm{ml} \mathrm{kg}^{-1} \mathrm{~min}^{-1}$ per additional $\mathrm{min} /$ day of MVPA. Nevertheless, it should be noted that in children from CI and TZ, the association between MVPA and CRF was only significant for girls. Furthermore, among girls from CI and TZ, CRF was only associated with VPA, but not with MPA. This contrasts with findings observed in our ZA sample, in which MPA were more closely associated with children's CRF. The reason why VPA was not significantly associated with $\mathrm{CRF}$ in children from $\mathrm{ZA}$ is not entirely clear. It is 
conceivable that the generally high MVPA and CRF levels (particularly among boys) may have complicated the detection of significant association between these variables (due to limited inter-individual variation).

The strengths of our study were that PA and CRF were assessed objectively, data from three different countries were considered, analyses were controlled for potential confounders (sex, age, BMI, and wear time), and mixed linear models accounted for the nested nature of the data. Moreover, although we had to exclude a substantial number of learners due to missing data and although we were not able to achieve similar sample sizes in each study site, the final samples were still relatively large (between 499 and 1,074 children per country). Future studies should include longitudinal data to gain further insights about cause and effect. We do acknowledge that the samples of the three study sites are not representative for their country, which complicates between-country comparisons, as multiple (unassessed) factors might have influenced the findings. For instance, although children were assessed from settings that were classified as "peri-urban" in each country, "peri-urban" might refer to different standards in the three countries. Another limitation is a potential selection bias as schools (clusters) were selected considering logistical/operational reasons and not truly at random. Lastly, we acknowledge that in the present analyses, we did not consider socioeconomic status as a potential confounder. Such analyses are currently underway, and will be presented elsewhere.

\section{CONCLUSIONS}

Most children involved in our study from three African countries met current PA standards (above 75\%) and achieved high CRF levels. Although the samples are not representative for the three countries included here, we observed that children living in the most urbanized setting (ZA) were physically less active and had lower CRF than peers living in more rural areas (from CI and TZ). Because PA differences were particularly found between boys and girls who live in the most urbanized setting, our findings suggest that urbanization might increase the risk for girls to not engage in sufficient MVPA. Therefore, girls should be seen as a particularly relevant target group for health interventions, especially as regular PA might contribute to the maintenance of good CRF, with positive implications for health and well-being in older age.

\section{DATA AVAILABILITY STATEMENT}

The raw data supporting the conclusions of this article will be made available by the authors, without undue reservation.

\section{ETHICS STATEMENT}

The studies involving human participants were reviewed and approved by In Côte d'Ivoire, the study protocol was approved by the Institutional Review Board (IRB) of the Centre Suisse de Recherches Scientifiques en Côte d'Ivoire
(CSRS; Abidjan, Côte d'Ivoire) and the Comité National d'Ethique des Sciences de la Vie et de la Santé (CNESVS; reference number: 100-18/MSHP/CVESVS-km). In South Africa, approval was granted by the research ethics committee of the Nelson Mandela University in Gqeberha (reference number: H18-HEA-HMS-006) and the Eastern Cape Departments of Education and Health. In Tanzania, the study protocol was approved by the responsible ethics committee at the Ifakara Health Institute (IHI-IRB; reference number: \# IHI/IRB/No 39-2018), the National Institute for Medical Research (NIMR; reference number: NIMR/HQ/R.8a/Vol. IX/3137) and the Tanzania Food and Drugs Authority (TFDA; reference number: TMDA0019/CTR/0016/05). Children who suffered from severe medical conditions and/or malnourishment (as diagnosed by a nurse, following national guidelines) were referred to local clinics. Ethical approval was also obtained from the Ethikkommission Nordwest- und Zentralschweiz in Switzerland (EKNZ; reference number: Req-2018-00608), and the intervention study was registered in the ISRCTN registry (http://www.isrctn.com/ISRCTN29534081). Written informed consent to participate in this study was provided by the participants' legal guardian/next of kin.

\section{AUTHOR CONTRIBUTIONS}

MG, KL, UP, and JU designed the study. MG serves as principal investigator of the study, performed the statistical analysis, and wrote the first draft of the manuscript. $\mathrm{BB}, \mathrm{HM}$, and $\mathrm{CW}$ are the principal investigators in the three partner countries. CL is responsible for the overall coordination of the study. ST, MF, and SN are the local coordinators. RdR, DD, KL, FO, NP-H, UP, and PS served as project advisors. SA, JB, BK, BG, ST, JC, MF, EM, SG, GM, CL, IM, and SN contributed to the data assessment and processing. All authors contributed to manuscript revision, read, and approved the submitted version.

\section{FUNDING}

This study was funded by the Fondation Botnar (Basel, Switzerland; grant number: 6071).

\section{ACKNOWLEDGMENTS}

We thank Larissa Adams, Nandi Joubert, Madeleine Nienaber, Danielle Smith, Zaahira Ismail, Salehe Makuka, Haji Fuko, Emmanuel Mrimi, Irene Ngoja, Anna Nyoni, and Jerôme N'Dri for their contribution to data collection. We also thank Jan Degen and all involved MSC students from the University of Basel, Switzerland (Lisa von Polanen, Nora Degonda, Ilir Freitag, and Selma Catakovic) and the University of Vienna, Austria (Christina Polak and Dominique Greger) for their support in the data collection and processing. We are grateful to the school authorities, school principals, teachers, medical doctor, nurses, teacher coaches, students, and parents/legal guardians for their willingness to enthusiastically supporting our study. 


\section{REFERENCES}

1. Aubert S, Barnes JD, Abdeta C, Nader PA, Adeniyi AF, Aguilar-Farias N, et al. Global matrix 3.0 physical activity report card grades for children and youth: results and analysis from 49 countries. J Phys Act Health. (2018) 15:S251-73. doi: 10.1123/jpah.2018-0472

2. Caspersen CJ, Powell KE, Christenson GM. Physical activity, exercise and physical fitness: definitions and distinctions for health-related research. Public Health Rep. (1985) 100:126-31.

3. Chakravarthy MV, Booth FW. Eating, exercise, and "thrifty" genotypes: connecting the dots toward an evolutionary understanding of modern chronic diseases. J Appl Physiol. (2004) 96:3-10. doi: 10.1152/japplphysiol.00757.2003

4. Kriemler S, Zahner L, Schindler C, Meyer U, Hartmann T, Hebestreit H, et al. Effect of school based physical activity programme (KISS) on fitness and adiposity in primary schoolchildren: cluster randomised controlled trial. $B M J$. (2010) 340:c785. doi: 10.1136/bmj.c785

5. McVeigh JA, Norris SA, de Wet T. The relationship between socio-economic status and physical activity patterns in South African children. Acta Paediatr. (2004) 93:982-8. doi: 10.1111/j.1651-2227.2004.tb02699.x

6. Pühse U, Gerber M. International Comparison of Physical Education. Concepts, Problems, Prospects. Aachen: Meyer \& Meyer. (2005).

7. Bull FC, Al-Ansari SS, Biddle SJ, Borodulin K, Buman MP, Cardon $\mathrm{G}$, et al. World Health Organization 2020 guidelines on physical activity and sedentary behaviour. Br J Sports Med. (2020) 54:1451-62. doi: $10.1136 /$ bjsports-2020-102955

8. Ludyga S, Gerber M, Pühse U, Looser V-N, Kamijo K. Long-term effects of exercise on cognition in healthy individuals are moderated by sex, exercise type and dose. Nat Hum Behav. (2020) 4:603-12. doi: 10.1038/s41562-020-0851-8

9. Poitras VJ, Gray CE, Borghese MM, Carson V, Chaput JP, Janssen I, et al. Systematic review of the relationships between objectively measured physical activity and health indicators in school-aged children and youth. Appl Physiol Nutr Metab. (2016) 41:S197-239. doi: 10.1139/apnm2015-0663

10. Salvini M, Gall S, Müller I, Walter C, Du Randt R, Steinmann P, et al. Physical activity and health-related quality of life among schoolchildren from disadvantaged neighbourhoods in Port Elizabeth, South Africa. Qual Life Res. (2018) 27:205-16. doi: 10.1007/s11136-017-1707-1

11. Gall S, Adams L, Joubert N, Ludyga S, Müller I, Nqweniso S, et al. Effect of a 20-week physical activity intervention on selective attention and academic performance in children living in disadvantaged neighborhoods in Port Elizabeth, South Africa. PLoS ONE. (2018) 13:206908. doi: 10.1371/journal.pone. 0206908

12. Nqweniso SCW, du Randt R, Aerts A, Adams L, Degan J, Gall S, et al. Prevention of overweight and hypertension through cardiorespiratory fitness and extracurricular sport participation among South African schoolchildren. Sustainability. (2020) 12:6581. doi: 10.3390/su12166581

13. Gerber M, Müller I, Walter C, Du Randt R, Adams L, Gall S, et al. Physical activity and dual disease burden among South African primary schoolchildren from disadvantaged neighbourhoods. Prev Med. (2018) 112:104-10. doi: 10.1016/j.ypmed.2018.04.001

14. Müller I, Walter C, du Randt R, Aerts A, Adams L, Degen J, et al. Association between physical activity, cardiorespiratory fit-ness and clustered cardiovascular risk in South African children from disadvantaged communities: results from a cross-sectional study. BMJ Open Sport Exerc Med. (2020) 0:e000823. doi: 10.1136/bmjsem-2020-000823

15. Elgar FJ, Pförtner TK, Moor I, De Clercq B, Stevens GW, Currie C. Socioeconomic inequalities in adolescent health 2002-2010: a time-series analysis of 34 countries participating in the Helath Behaviour in School-aged Children study. Lancet. (2015) 385:2088-95. doi: 10.1016/S0140-6736(14)61460-4

16. Carson V, Hunter S, Kuzik N, Grax CE, Poitras VJ, Chaput JP, et al. Systematic review of sedentary behaviour and health indicators in school-aged children and youth: an update. Appl Physiol Nutr Metab. (2016) 41:S240-65. doi: 10.1139/apnm-2015-0630

17. Muthuri SK, Wachira LJ, Leblanc AG, Francis CE, Sampson M, Onywera VO, et al. Temporal trends and correlates of physical activity, sedentary behavior, and physical fitness among school-aged children in Sub-Saharan
Africa: a systematic review. Int J Environ Res Public Health. (2014) 11:3327-59. doi: 10.3390/ijerph110303327

18. Guthold R, Stevens GA, Riley LM, Bull FC. Global trends in insufficient physical activity among adolescents: a pooled analysis of 298 population-based surveys with 1.6 million participants. Lancet Child Adolesc Health. (2020) 4:23-35. doi: 10.1016/S2352-4642(19)30323-2

19. Darfour-Oduro SA, Buchner DM, Andrade JE, Grigsby-Toussaint DS. A comparative study of fruit and vegetable consumption and physical activity among adolescents in 49 low-and-middle-income countries. Sci Rep. (2018) 8:1623. doi: 10.1038/s41598-018-19956-0

20. Bénéfice E, Ndiaye G. Relationship between anthropometry, cardiorespiratory fitness indices and physical activity levels in different age and sex groups in rural Senegal (West Africa). Ann Hum Biol. (2005) 32:366-82. doi: $10.1080 / 03014460500097336$

21. Reilly JJ. When does it all go wrong? Longitudinal studies of changes in moderate-to-vigorous-intensity physical activity across childhood and adolescence. J Exerc Sci Fit. (2016) 14:1-6. doi: 10.1016/j.jesf.2016.05.002

22. Lamprecht M, Fischer M, Stamm M. Sport Schweiz 2008. Kinder- und Jugendbericht. Magglingen: BASPO. (2008).

23. Cooper AR, Goodman A, Page AS, Sherar LB, Esliger DW, van Sluijs E, et al. Objectively measures physical activity and sedentary time in youth: the International Children's Accelerometry Database (ICAD). Int J Behav Nutr Phys Act. (2015) 12:113. doi: 10.1186/s12966-015-0274-5

24. Corder K, Sharp SJ, Atkin AJ, Andersen LB, Cardon G, Page A, et al. Age-related patterns of vigorous-intensity physical activity in youth: the International Children's Accelerometry Database. Prev Med Rep. (2016) 4:1722. doi: 10.1016/j.pmedr.2016.05.006

25. Mountjoy M, Andersen LB, Armstrong N, Biddle SJ, Boreham C, BrandlBredenbeck HP, et al. International Olympic Committee consenus statement on the health and fitness of young people through physical activity and sport. Br J Sports Med. (2011) 45:839-48. doi: 10.1136/bjsports-2011-090228

26. Nigg C, Fuchs R, Gerber M, Jekauc D, Koch T, Krell-Koch J, et al. Assessing physical activity through questionnaires - consensus of best practice and future directions. Psychol Sport Exerc. (2020) 50:101715. doi: 10.1016/j.psychsport.2020.101715

27. Lang C, Kalak N, Brand S, Holsboer-Trachsler E, Pühse U, Gerber M. The relationship between physical activity and sleep from mid adolescence to early adulthood. A systematic review of methodological approaches and metaanalysis. Sleep Med Rev. (2016) 58:32-45. doi: 10.1016/j.smrv.2015.07.004

28. Reilly JJ, Penpraze V, Hislop J, Davies G, Grant S, Paton JY. Objective measurement of physical activity and sedentary behavioiur: review with new data. Arch Dis Child. (2008) 93:614-9. doi: 10.1136/adc.2007.133272

29. Lang JJ, Wolfe Philips E, Orpana HM, Tremblay MS, Ross R, Ortega $\mathrm{FB}$, et al. Field-based measurement of cardiorespiratory fitness to evaluate physical activity. Bull World Health Organ. (2018) 96:794-6. doi: 10.2471/BLT.18.213728

30. Armstrong N, Tomkinson GR, Ekelund U. Aerobic fitness and its relationship to sport, exercise training and habitual physical activity during youth. $\mathrm{BrJ}$ Sports Med. (2011) 45:849-58. doi: 10.1136/bjsports-2011-090200

31. Armstron N, Welsman JR, Kirby BJ. Peak oxygen uptake and maturation in 12-yr olds. Med Sci Sports Exerc. (1998) 30:165-9. doi: 10.1097/00005768-199801000-00023

32. Müller I, Coulibaly JT, Fürst T, Knopp S, Hattendorf J, Krauth SJ, et al. Effect of schistosomiasis and soil-transmitted helminth infections on physical fitness of school children in Côte d'Ivoire. PLoS Negl Trop Dis. (2011) 5:e1239. doi: 10.1371/journal.pntd.0001239

33. Olds TS, Tomkinson GR, Léger L, Cazorla G. Worldwide variation in the performance of children and adolescents: an analysis of 109 studies of the 20-m shuttle run test in 37 countries. J Sports Sci. (2006) 24:1025-38. doi: 10.1080/02640410500432193

34. Nottin S, Vinet A, Stecken F, N'Guyen L-D, Ounissi F, Lecoq A$\mathrm{M}$, et al. Central and peripheral cardiovascular adaptations to exercise in endurance-trained children. Acta Physiol Scand. (2002) 175:85-92. doi: 10.1046/j.1365-201X.2002.00975.x

35. van Ekris E, Altenburg TM, Singh AS, Proper KI, Heymans MW, Chinapaw MJ. An evidence-update on the prospective relationship between childhood sedentary behaviour and biomedical health indicators: a systematic review and meta-analysis. Obes Rev. (2016) 17:833-49. doi: 10.1111/obr.12426 
36. Christensen DL, Faurholt-Jepsen D, Boit MK, Mwaniki DL, Kilonzo B, Tetens I, et al. Cardiorespiratory fitness and physical activity in Luo, Kamba, and Maasai of rural Kenya. Am J Hum Biol. (2012) 24:723-9. doi: 10.1002/ajhb.22303

37. Gerber M, Ayekoé SA, Beckmann J, Bonfoh B, Coulibaly JT, Daouda D, et al. Effects of school-based physical activity and multi-micronutrient supplementation intervention on growth, health and well-being of schoolchildren in three African countries: the KaziAfya cluster randomised controlled trial protocol using a 2x2 factorial design. Trials. (2020) 21:5. doi: 10.1186/s13063-019-3883-5

38. Hills AP, Mokhtar N, Byrne NM. Assessment of physical activity and energy expenditure: an overview of objective measures. Front Nutr. (2014) 15:5. doi: 10.3389/fnut.2014.00005

39. Aadland E, Andersen LB, Skrede T, Ekelund U, Anderssen SA, Resaland GK. Reproducibility of objectively measured physical activity and sedentary time over two seasons in children; comparing a day-by-day and a week-byweek approach. PLoS ONE. (2017) 12:e0189304. doi: 10.1371/journal.pone. 0189304

40. Troiano RP, Berrigan D, Dodd KW, Mâsse LC, Tilert T, McDowell M. Physical activity in the United States measured by accelerometer. Med Sci Sports Exerc. (2008) 40:181-8. doi: 10.1249/mss.0b013e31815a51b3

41. Clemente FM, Nikolaidis PT, Martins FM, Mendes RS. Physical activity patterns in university students: do they follow the public health guidelines? PLoS ONE. (2016) 11:152516. doi: 10.1371/journal.pone.0152516

42. Evenson KR, Catellier DJ, Gill K, Ondrak KS, McMurray RG. Calibration of two objective measures of physical activity for children. J Sports Sci. (2008) 26:1557-65. doi: 10.1080/02640410802334196

43. Léger LA, Mercier D, Gadoury C, Lambert J. The multistage 20 meter shuttle run test for aerobic fitness. J Sports Sci. (1988) 6:93-101. doi: 10.1080/02640418808729800

44. West SG, Finch JF, Curran PJ. Structural equation models with nonnormal variables: problems and remedies. In: Hoyle RH, editor, Structural Equation Modeling. Concepts, Issues, and Applications (Thousand Oakes, CA: Sage) (1995). p. 56-75.

45. Onywera VO, Adamo KB, Sheel AW, Waudo JN, Boit MK, Tremblay M. Emerging evidence of the physical activity transition in Kenya. J Phys Act Health. (2012) 9:554-62. doi: 10.1123/jpah.9.4.554

46. Botha CR, Wright HH, Moss SJ, Kolbe-Alexander TL. "Be active!" Revising the South African food based dietary guideline for activity. SA J Clin Nutr. (2013) 26:S18-27.

47. Ruiz JR, Cavero-Redondo I, Ortega FB, Welk GJ, Andersen LB, MartinezVizcaino V. Cardiorespiratory fitness cut points to avoid cardiovascular disease risk in children and adolescents: what level of fitness should raise a red flag? A systematic review and meta-analysis. Br J Sports Med. (2016) 50:1451-8. doi: 10.1136/bjsports-2015-095903

48. Lang JJ, Tremblay MS, Léger L, Olds T, Tomkinson GR. International variability in $20 \mathrm{~m}$ shuttle run performande in children and youth: who are the fittest from a 50-country comparison? A systematic literature review with pooling of aggregate results. Br J Sports Med. (2018) 52:276. doi: 10.1136/bjsports-2016-096224

49. Adebusoye B, Phalkey R, Leonardi-Bee J, Chattopadhyay K. Association of the built environment with physical activity in children and adolescents in Africa: a systematic review. JBI Evid Synth. (2020) 18:553-63. doi: 10.11124/JBISRIR-D-19-00162

50. United Nations. United Nations Expert Group Meeting on Population Distribution, Urbanization, Internal Migration and Development. New York, NY: United Nations (2008).

51. Kidokoro T, Fuku N, Yanagiya T, Takeshita T, Takaragawa M, Annear M, et al. Physical activity and sedentary behaviour patterns among Kenyan and Japanese children: a comprehensive cross-country comparison. Int J Environ Res Public Health. (2020) 17:4254. doi: 10.3390/ijerph17124254

52. Armstrong N, Welsman J. Development of peak oxygen uptake from 11-16 years determined using both treadmill and cycle ergometry. Eur J Appl Physiol. (2019) 119:801-12. doi: 10.1007/s00421-019-04071-3
53. Vinet A, Mandigouit S, Nottin S, Nguyen L, Lecoq A-M, Courteix D, et al. Influence of body composition, hemoglobin concentration, and cardiac size and function of gender differences in maximal oxgen uptake in prepubertal children. Chest. (2003) 124:1494-9. doi: 10.1378/chest.124.4.1494

54. McNarry MA, Farr C, Middlesbrooke A, Welford D, Breese B, Armstrong $\mathrm{N}$, et al. Aerobic function and muscle deoxygenation dynamics during ramp exercise in children. Med Sci Sports Exerc. (2015) 47:1877-84. doi: 10.1249/MSS.0000000000000609

55. Draper CE, Tomaz SA, Harbron J, Kruger HS, Micklesfield LK, Monyeki A, et al. Results from the healthy active kids South Africa 2018 report card. SA J Child Health. (2019) 13:130-6. doi: 10.7196/SAJCH.2019.v13 i3. 1640

56. Uys M, Bassett S, Draper CE, Micklesfield LK, Monyeki A, de Villiers A, et al. Results from South Africa's 2016 report card on physical activity for children and youth. J Phys Act Health. (2016) 13:S265-73. doi: 10.1123/jpah. 2016-0409

57. McVeigh J, Meiring R. Physical activity and sedentary behavior in an ethnically diverse group of South African school children. J Sport Sci Med. (2014) 13:371-8.

58. Armstrong N, Welsman J. Youth cardiorespiratory fitness: evidence, myths and misconceptions. Bull World Health Organ. (2019) 97:777-82. doi: 10.2471/BLT.18.227546

59. Armstrong N, Williams J, Ringham D. Peak oxygen uptake and progressive shuttle run performance in boys aged 11-14 years. Br J Phys Edu. (1988) 19:10-1.

60. Castro-Pinero J, Artero EG, Espana-Romero V, Ortega FB, Sjöström M, Suni J, et al. Criterion-related validity of field-based fitness tests in youth: a systematic review. Br J Sports Med. (2010) 44:934-43. doi: 10.1136/bjsm.2009. 058321

61. Ortega FB, Ruiz JR, Castillo MJ, Sjöström M. Physical fitness in childhood and adolescence: a powerful marker of health. Int J Obes. (2008) 32:1-11. doi: $10.1038 /$ sj.ijo.0803774

62. Ruiz JR, Castro-Pinero J, Artero EG, Ortega FB, Sjöström M, Suni J, et al. Predictive validity of health-related fitness in youth: a systematic review. $\mathrm{Br}$ J Sports Med. (2009) 43:909-23. doi: 10.1136/bjsm.2008.056499

63. Judice PB, Silva AM, Berria J, Petroski EL, Ekelund U, Sardinha LB. Sedentary patterns, physical activity and health-related physical fitness in youth: a cross-sectional study. Int J Behav Nutr Phys Act. (2017) 14:25. doi: 10.1186/s12966-017-0481-3

64. Morrow JRJ, Tucker JS, Jackson AW, Martin SB, Greenleaf CA, Petrie TA. Meeting physical activity guidelines and health-related fitness in youth. Am J Prev Med. (2013) 44:439-44. doi: 10.1016/j.amepre.2013. 01.008

Conflict of Interest: The authors declare that the research was conducted in the absence of any commercial or financial relationships that could be construed as a potential conflict of interest.

Publisher's Note: All claims expressed in this article are solely those of the authors and do not necessarily represent those of their affiliated organizations, or those of the publisher, the editors and the reviewers. Any product that may be evaluated in this article, or claim that may be made by its manufacturer, is not guaranteed or endorsed by the publisher.

Copyright (c) 2021 Gerber, Ayekoé, Beckmann, Bonfoh, Kouassi, Gba, Traoré, Coulibaly, Daouda, du Randt, Finda, Minja, Gall, Mollel, Lang, Long, Masanja, Müller, Nqweniso, Okumu, Probst-Hensch, Pühse, Steinmann, Walter and Utzinger. This is an open-access article distributed under the terms of the Creative Commons Attribution License (CC BY). The use, distribution or reproduction in other forums is permitted, provided the original author(s) and the copyright owner(s) are credited and that the original publication in this journal is cited, in accordance with accepted academic practice. No use, distribution or reproduction is permitted which does not comply with these terms. 